\title{
Type A Acute Aortic Dissection in Nonagenarian: Rare but Possible
}

\section{Dissezione acuta aortica tipo $A$ in un nonagenario: rara ma possibile}

\author{
Rodolfo Citro, Marco Mariano Patella, Gennaro Provenza, \\ Giovanni Gregorio, Eduardo Bossone ${ }^{1}$
}

\begin{abstract}
Type A Acute Aortic Dissection in Nonagenarian: Rare but Possible. R. Citro, M. Mariano Patella, G. Provenza, G. Gregorio, E. Bossone.

Acute type A aortic dissection (TA-AAD) is a highly lethal clinical entity that can occur within a wide age range, associated with multiple aetiologies and various clinical presentations. In the very elderly type A aortic dissection frequently presents with non-specific symptoms and signs and
\end{abstract}

is associated with high mortality and morbidity. Thus the clinician must have a high index of clinical suspicion in order to prompt the most appropriate diagnostic-therapeutic strategy.We report a nonagenarian women with TA-AAD, treated successfully with medical therapy.

Keywords: acute aortic dissection, elderly, outcome.

Monaldi Arch Chest Dis 2007; 68: 184-185.

Dipartimento di Cardiologia, Ospedale San Luca, Vallo della Lucania, Salerno, Italy.

* Divisione di Cardiologia, Cava de' Tirreni - Costa d'Amalfi, Salerno, Italy.

Corresponding author: Prof. Eduardo Bossone; Via Principe Amedeo - I-3683023 Lauro (AV), Italy; E-mail address: ebossone@hotmail.com

The rapidly increasing population of elderly patients in the Western world and the growing age-related incidence of ischemic, degenerative, and calcific valve disease have led to a significant number of very elderly referred for cardiac surgery [1]. Acute type A aortic dissection (TA-AAD) is an uncommon lethal cardiovascular emergency that demands prompt diagnosis and aggressive surgical intervention. Yet, a substantial number of patients affected by this disease (25-30\%) does not receive surgery, either because of their advanced age, comorbidity, or refusal to undergo the procedure $[2,3]$. We report a nonagenarian women with TA-AAD treated successfully with medical therapy.

\section{Case report}

A 91-year-old hypertensive woman was referred to our emergency department because of 10-day history of increasing dyspnoea (NYHA class III). On physical examination, her blood pressure was 160/60 mm Hg and the heart rate was regular at 92 beats/min; a grade III/VI diastolic murmur was heard along the left sternal border and rales were heard at lung bases; no pulse deficit was noted. Chest radiography showed widened mediastinum and the resting 12-lead electrocardiogram was suggestive for left ventricular hypertrophy. A transthoracic bidimensional color Doppler echocardiography examination, performed in the emergency room, visualized two lumina separated by an intimal flap within a dilated ascending aorta (TA-AAD), moderate aortic regurgitation, mild dilated and hypertrophied left ventricle without segmental or global wall motion abnormalities. No periaortic, pericardial, or pleural fluid extravasation was detected. The patient re- fused transesophageal echocardiography and underwent computed tomography which confirmed the diagnosis of TA-AAD. Because of the very advanced age, the patient was started on nitrates, diuretics, and ACEinhibitors. After two weeks, the patient was discharged from the hospital in stable clinical conditions and on treatment with ACE-inhibitors, diuretics and betablockers. At two years follow-up, the patient is doing well (NYHA class II) and with no complications.

\section{Discussion}

Despite recent progress in diagnostic and therapeutic intervention, TA-AAD remains a very serious vascular emergency that carries substantial in-hospital mortality and morbidity - even in centers with extensive expertise in treating this disease [3]. Along with signs and/or symptoms of organ malperfusion and clinical instability (pulse deficits, renal failure, hypotension and/or shock), age $\geq 70$ years represents a strong predictor of in-hospital mortality for TA-AAD $[4,5]$.

In the IRAD registry, compared to younger patients ( $<70$ years), elderly patients ( $\geq 70$ years) were more likely to have a medical history of systemic arterial hypertension, atherosclerosis, diabetes and previous cardiac surgery, and less likely to present with typical symptoms (abrupt onset of chest or back pain) and signs (aortic regurgitation or pulse deficit). Furthermore, they were less likely to be managed surgically (64\% vs. $86 \%$ ) and had an higher in hospital mortality (48\% vs 28\%) [5]. Our single case of a nonagenarian suffering of TA-AAD, treated successfully with medical therapy, along with other reports highlight important "clues" of AAD in octogenarians and over. In the very elderly patients, AAD 
may present with atypical features, while bearing a higher morbility and mortality as compared with younger patients [5]. Therefore, the clinician must have a very high clinical index of suspicion in order to prompt the most appropriate diagnostic and therapeutic strategy. To this regard, it has to be underlined that the choice between medical and surgical intervention in the aged patient should be based on the individual case, taking into consideration frequent comorbid conditions, the higher risks of post surgical complications (in particular neurogical deficits and dementia) and the fragility of aortic wall. Moreover, whichever the strategy adopted, the complete treatment for such patients will have to entail a close follow-up including a long-term antihypertensive medical therapy aimed to lower blood pressure, aortic wall stress, and left ventricular contractility, as well as serial imaging to detect life threatening complications.

\section{Riassunto}

La dissezione aortica acuta tipo A (TA-AAD) è una entità clinica altamente letale che può presentarsi in un ampio range di età, associata a varie etiologie e diverse presentazioni cliniche. Nel paziente molto anziano la TA$A A D$ frequentemente si presenta con sintomi e segni clinici non specifici, ed è associata ad elevata mortalità. Pertanto in questi casi il clinico deve avere un alto indice di sospetto clinico per predisporre le più adatte strategie diagnostico-terapeutiche. Qui riportiamo il caso di una donna nonagenaria con TA-AAD, trattata con successo con terapia medica.

\section{References}

1. Bossone E, Di Benedetto G, Frigiola A, et al. Valve surgery in octogenarians: In-hospital and long-term outcomes. Can J Cardiol 2007; 23: 223-7.

2. Erbel R, Alfonso F, Boileau C, et al. Diagnosis and management of aortic dissection: task force report of the European Society of Cardiology. Eur Heart J 2001; 22: $1642-1681$

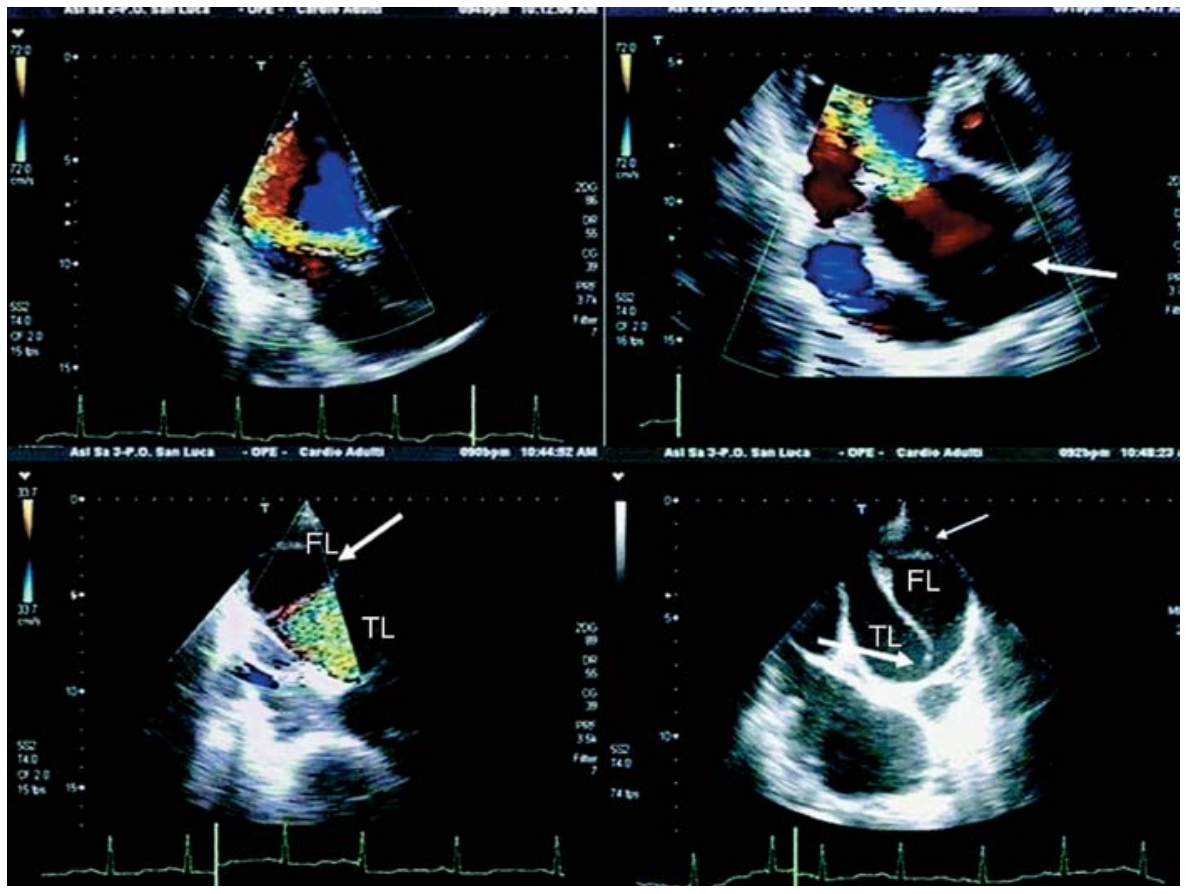

Figure 1. - Top. Left panel. Apical long axis view depicting a wide turbulent color flow jet caused by severe aortic regurgitation. The height of the origin of the jet takes up nearly all the left ventricular outflow tract. Right panel. A modified apical long axis view section better visualizes the proximal ascending aorta demonstrating an intimal flap extending from the anterior aortic wall to the sinotubular

Bottom. Left panel. Suprasternal modified long-axis view showing the distal tract of ascending aorta. Intimal flap separating true lumen from false lumen can be appreciated. By using a scale of colorDoppler with a limit of Nyquist of $33 \mathrm{~cm} / \mathrm{sec}$, it is evident slow flow into the false lumen (red color; see arrow) characterized by lower velocity compared with the turbulent flow of the true lumen. Right panel A short axis right subclaviclear section, obtained by moving the probe toward caudal direction from the previous view, demonstrates a communicating dissection caused by an entry tear (see arrow). A thrombus formation is noticeable in the false lumen (see small arrow).

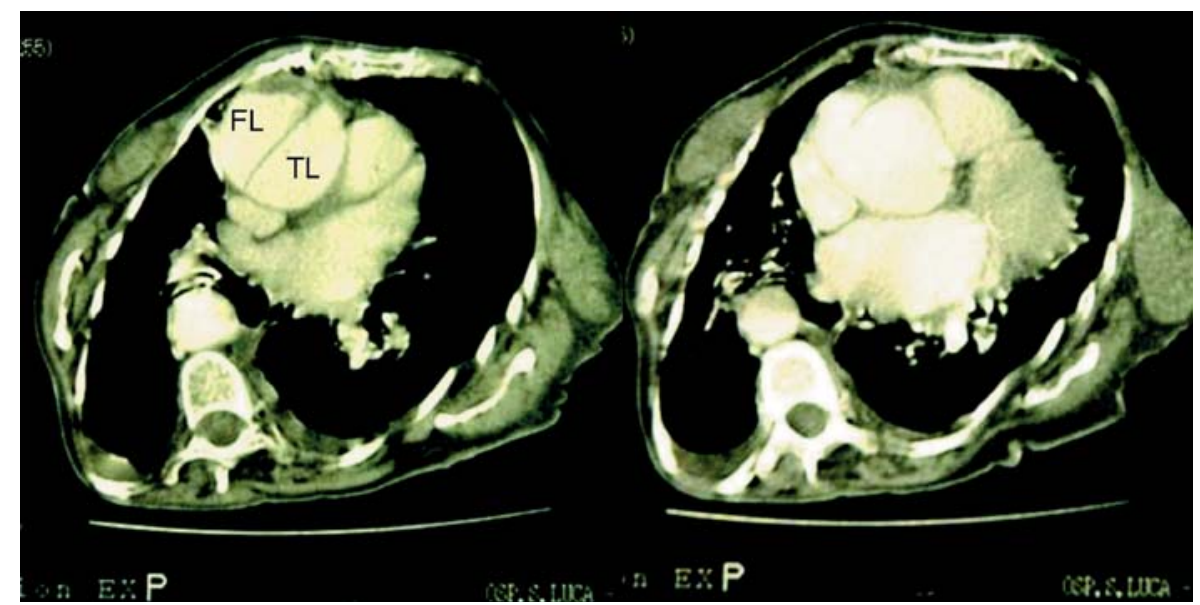

Figure 2. - Left panel. Contrast enhanced computed tomography scan of the chest at level of the right pulmonary artery demonstrating a linear structure (intimal flap) in the ascending aortic lumen, which separates the true from the false channel; note the thrombus in the false lumen. Right panel. A lower slice demonstrates a communicating dissection (tear) of the ascending aorta.

3. Hagan PG, Nienaber CA, Isselbacher EM, et al. The International Registry of Acute Aortic Dissection (IRAD): new insights into an old disease. JAMA 2000; 283: 897-903.

4. Mehta R H, Suzuki T, Hagan P G, et al. Predicting death in patients with acute type A aortic dissection. Circulation 2002; 105: 200-206.

5. Mehta R H, O'Gara P T, Bossone E, et al. Acute type A aortic dissection in the elderly: clinical characteristics, management, and outcomes in the current era. J Am Coll Cardiol 2002; 40: 685-692. 